\title{
O transtorno bipolar na rede: a construção do diagnóstico em um grupo on-line
}

| ${ }^{1}$ Luisa Motta Corrêa, ${ }^{2}$ Rossano Cabral Lima |

Resumo: O artigo aborda os significados e sociabilidades que um grupo do Facebook sobre o transtorno bipolar tem produzido em torno deste diagnóstico, através de uma etnografia virtual. Junto à crescente penetração dos referenciais psiquiátricos na cultura, a bipolaridade vem se disseminando por meios como a internet e participando do modo como inúmeras pessoas interpretam e experimentam suas oscilaçôes emocionais. A etnografia buscou investigar os impactos do diagnóstico na compreensão de si, os tons em que os participantes falam dele, os tratamentos e concepçôes sobre natureza/causas da bipolaridade abordados etc. Foram analisadas as dez publicaçóes mais comentadas do grupo no período de um mês e, com base nos diferentes eixos temáticos identificados, chegou-se ao seguinte resultado: a maioria dos relatos traz experiências dolorosas, situando a bipolaridade como obstáculo a ser contornado; o endosso e identificação mútua pelo diagnóstico são frequentes no grupo, estimulando o companheirismo; os medicamentos são o recurso privilegiado no tratamento do transtorno, que é visto como incurável, mas passível de regulação; o cultivo de pensamentos e atitudes positivos são algumas das estratégia usadas para contornar as fases difíceis, mostrando uma postura pragmática em relação ao sofrimento psíquico; a bipolaridade é definida como uma entidade externa à personalidade.

> Palavras-chave: transtorno bipolar; ativismo em saúde; internet; comunidade virtual.

\author{
1 Saúde Mental, CAPS \\ Profeta Gentileza, Inhoaíba. \\ Rio de Janeiro-RJ, Brasil \\ (luisamottacorrea@gmail.com). \\ ORCID: 0000-0001-6350-5979 \\ ${ }^{2}$ Instituto de Medicina Social, \\ Universidade do Estado do Rio \\ de Janeiro. Rio de Janeiro-RJ, \\ Brasil (rossanolima1@gmail.com). \\ ORCID: 0000-0002-8583-4535
}

Recebido em: 19/03/2018 Aprovado em: 09/08/2018 Revisado em: 17/09/2018 


\section{Introdução}

Desde o fim da Segunda Guerra Mundial (1939-1945), vêm se formando movimentos e associaçóes de portadores de doenças físicas ou mentais dedicados a reivindicar direitos e tratamentos. Nas palavras de Rabinow e Rose (2006), "vimos o surgimento de novos tipos de grupos de pacientes e indivíduos, que cada vez mais definem a sua cidadania em termos de seus direitos (e obrigaçôes) à vida, saúde e cura" (p. 37). Dentre esses grupos, muitos se formaram em torno de um status corporal ou genético compartilhado, constituindo biossociabilidades (RABINOW, 1999, 2008). Junto ao advento desta posição mais ativa por parte dos pacientes, delineou-se também um novo modo de lidar consigo e construir identidades, fortemente articulado aos saberes médicos e biológicos. No caso dos transtornos mentais, estas transformaçôes se associaram à difusão dos manuais de psiquiatria, como o CID (Classificação Internacional de Doenças) e o DSM (Manual Diagnóstico e Estatístico de Transtornos Mentais), na sociedade e na cultura.

Um ator que merece destaque nesta conjuntura é a internet, tanto por proporcionar um rápido e fácil acesso às informaçóes em saúde, quanto pela diversidade de canais de discussão e interação que oferece para seus usuários. De acordo com Barker (2008), este meio de comunicação é uma das fontes principais de informação em saúde e medicina atualmente. Há milhares de sites sobre o tema, que é o sexto mais abordado na internet (AYERS; KRONENFELD, 2007).

Segundo esses autores (ibidem), o recurso mais usado por aqueles que buscam assistência em saúde on-line é o acesso a grupos de suporte emocional que abordam uma doença específica e ajudam o doente a encontrar caminhos para lidar com sua condição. Para Barker (2008), esses grupos são um componente-chave no que se convencionou chamar e-health, possibilitando aos indivíduos definirem coletivamente a natureza do seu problema e os possíveis caminhos para a sua solução. Nesse contexto, a compreensão de sofrimentos, angústias e enfermidades é transferida da relação privada entre médico e paciente para o intercâmbio coletivo no ciberespaço.

De acordo com Tanis (2008), os fóruns on-line fornecem informaçôes em saúde mais diversificadas do que as disponíveis no meio offline, ajudando os usuários a expandirem seus conhecimentos e a resolverem questôes e incertezas sobre seus problemas de saúde. Por sofrerem da mesma condição física ou mental, os participantes cultivam um sentimento de comunhão e uma relação de empatia que os estimula a 
expressar mais abertamente suas experiências. A relação com desconhecidos envolve menos preconceitos e expectativas recíprocas, tornando mais confortável o diálogo sobre doenças ou outros problemas. Desse modo, os fóruns virtuais inauguram um espaço de intimidade com estranhos, em que são construídos sentimentos de confiança e pertencimento tão essenciais para pessoas que têm suas relaçóes sociais comprometidas pela doença (TANIS, 2008).

Em direção semelhante, Hardey (1999) propóe que o anonimato proporcionado pelos grupos de autoajuda on-line facilita a construção de sentido para momentos de crise. Nas comunidades virtuais, pessoas com doenças crônicas ou debilitantes se abrem para estranhos, expressando suas questóes e sentimentos íntimos justamente porque são desconhecidas para aqueles com quem falam. Para Ortega et al. (2013), a possibilidade de interação anônima e virtual entre os usuários da internet modificou a própria experiência da doença para muitos pacientes e cuidadores.

No grupo on-line, há um saber que se formula para além das referências científicas. Este modo de conhecimento, produzido pelos pacientes e público leigo, foi objeto de novas nomenclaturas no âmbito da sociologia da saúde. Em relação aos fóruns interativos na internet, Tanis (2008) afirma que seus integrantes são "expert da experiência" e tornam-se, assim, boas fontes de informação. Outros termos criados para se referir aos indivíduos que se localizam no território fronteiriço com o saber científico, apropriando-se dele de modo ativo, foram "leigo especialista" (EPSTEIN, 1995; ORTEGA et al. 2013) e "paciente especialista" (FOX; WARD; O'ROURKE, 2005). Nas palavras de Ortega et al. (2013), o leigo-especialista é "o indivíduo que, embora não pertença ao campo da saúde, se encontra táo envolvido com a doença que é capaz de manejar o vocabulário médico, questionar, debater e dialogar com o saber médico" (p. 128). Em uma discussão sobre grupos e movimentos de pacientes, Epstein (2008) afirma que houve, em muitos casos, uma combinação entre o saber derivado da experiência e diferentes graus de conhecimento formal, produzindo uma variedade de expertises e formas de saber híbridas.

As consequências disso para a profissão médica são alvo de debate na literatura sobre o tema. Haug (1988) e Hardey (1999) defendem a tese da desprofissionalizaçáo, argumentando que a expansão do saber leigo desafia a autoridade e prestígio da medicina. Segundo Hardey (ibidem), o design da internet subverte modelos hierárquicos de difusão da informação, alterando os padrôes de controle do saber e contribuindo, assim, para o declínio da confiança estrita nos médicos. 
As transformaçôes na relação médico-paciente derivadas dessas mudanças foram analisadas por Broom (2005) a partir da tese do "empoderamento". Segundo o autor, a internet pode aumentar o senso de controle dos pacientes sobre a doença, o que gera impactos sobre o modo como se posicionam diante do médico.

Rose (2013) argumenta que a internet não apenas reproduz e propaga os referenciais biomédicos, mas também colabora para a sua reconfiguração e contestação. Se, por um lado, na última década este meio de comunicação levou pessoas que buscam informações sobre saúde e doença a um processo de automodelação biomédica; por outro, ele permitiu àqueles que sofrem de um comprometimento físico ou mental acessarem autonarrativas escritas por outros pacientes ou cuidadores. Na opinião do autor, estas construçôes "de baixo para cima” são capazes de pluralizar a verdade biomédica, produzindo dúvida e controvérsia, e "reposicionando a ciência nos campos da experiência, da política e do capitalismo” (ibidem, p. 202).

\section{Os transtornos mentais na rede}

No processo de formação de grupos e ativismos em torno de doenças mentais, os referenciais neurobiológicos vêm sendo absorvidos e ressignificados pelas pessoas que sofrem destas patologias ou se identificam com elas. A ampla difusão da psiquiatria - associada às neurociências - através da mídia permitiu que muitos indivíduos passassem a se diagnosticar por conta própria, apropriando-se do saber científico de forma inédita. Os efeitos disso no processo de construção identitária deram origem ao que Costa (2004) chamou de bioidentidades, ou seja, formas de se compreender e se nomear baseadas na biologia.

Junto à propagação da psiquiatria e das neurociências pela sociedade, passaram a se formar fóruns e comunidades on-line sobre alguns transtornos mentais. Um exemplo são aqueles sobre autismo, que apesar de terem sido amplamente debatidos em outros países, foram objeto de apenas uma pesquisa no Brasil, em que se investigou a opiniāo pública sobre o tema através de comunidades do Orkut. Segundo os autores, "a opinião pública sobre determinada condição médica traz consequências diretas sobre a experiência do doente e sobre as pessoas implicadas em cuidar dos pacientes acometidos" (ORTEGA et al., 2013, p. 119). Por ser um ambiente privilegiado na construção e circulação da opinião pública, a internet vem se tornado um espaço fundamental para a produção de sentido sobre o autismo e a experiência de ser parente de um autista. 
Concluiu-se nesse estudo que as comunidades do Orkut contribuem para criar uma forma própria de relação com a medicina, que demonstra respeito e interesse pelas concepçôes científicas sobre o autismo, mas, ao mesmo tempo, revela uma preponderância de relatos sobre a experiência pessoal com a doença. A ausência de um profissional especialista abre espaço para a criação de uma autoridade baseada na experiência, na figura do leigo-especialista, que produz teorias próprias sobre a doença e seus tratamentos.

Assim como no caso do autismo, o transtorno bipolar também vem sendo objeto de grupos virtuais. Apesar de o fenômeno ter um alcance significativo na atualidade, poucas pesquisas foram realizadas sobre o tema. Vayreda e Antaki (2009) investigaram, através da Conversation analysis (análise de conversação), um fórum on-line espanhol para bipolares, observando a relaçáo entre a primeira mensagem de um novo membro e a resposta obtida. Constatou-se que enquanto a postagem de apresentação do participante recém-chegado costumava trazer a revelação sobre a descoberta do novo diagnóstico, infelicidade com a notícia e um pedido de ajuda vago aos membros do grupo, a resposta obtida apresentava um conselho que não havia sido solicitado, recomendando, por exemplo, que a pessoa procurasse o psiquiatra. Antes desta recomendação, era comum a pessoa demonstrar ligação com o participante que fez a pergunta, revelando que também era bipolar ou fazendo algum comentário empático. Em alguns casos, a identificação como alguém que também sofre de bipolaridade se dava pelo uso da primeira pessoa do plural. Vayreda e Antaki (ibidem) concluíram que os conselhos diretivos buscavam conduzir o novo usuário ao modelo biomédico de tratamento, tendência que obedecia à ideologia promovida pela página da internet na qual o grupo era sediado.

Este foco estrito na abordagem biomédica não apareceu nos fóruns on-line alemães estudados por Bauer et al. (2013). Os autores analisaram 2.400 postagens em dois grupos para bipolares, concluindo que o motivo central para a participação era a busca por compartilhar emoçôes e discutir os embates diários com a doença. Os principais mecanismos de autoajuda construídos pelo grupo eram "disclosure" (autoexposição), "friendship" (amizade) e "online-group cohesion" (coesão do grupo on-line). Além da unidade grupal, o suporte emocional e a troca de informaçôes foram identificados como fatores relacionados aos mecanismos de autoajuda. Os assuntos mais discutidos eram rede social, sintomas do transtorno e medicação. Ao final, os autores concluíram que a rede social virtual é muito importante para o 
manejo do transtorno bipolar pelos pacientes e que os programas psicoeducacionais deveriam focar nos aspectos identificados através do estudo destas redes.

Constataçóes muito semelhantes foram tiradas a partir de um estudo de Schielein et. al (2008), que investigou 1.200 postagens de 135 usuários em dois fóruns online alemães, concluindo que os tópicos mais discutidos eram as redes sociais dos pacientes, os sintomas da doença e as medicações. Além disso, a autoexposição, a coesão grupal, bem como a empatia e o suporte foram as principais formas de autoajuda produzidas pelo grupo. Assim como Bauer et al. (2013), essa pesquisa concluiu que a rede social virtual ajuda os pacientes a lidarem com o transtorno bipolar e que o interesse central dos participantes é compartilhar emoções.

Outra pesquisa que investigou fóruns de discussão sobre o transtorno bipolar analisou páginas de discussão tchecas voltadas para pessoas com bipolaridade (LATALOVA et al., 2014), justificando a necessidade de fazê-lo pelo fato de não haver muita produção de conhecimento sobre iniciativas de autoajuda neste campo. Com base nesse levantamento, os autores tiraram algumas conclusóes. Uma delas foi que o benefício das páginas de discussão para bipolares é dar a eles uma oportunidade de abrir-se para o outro, de obter informação adicional, de compartilhar experiências, de se sentir pertencendo a uma comunidade, de aprender com outras pessoas, de aconselhar os demais etc. Há muitos diálogos sobre medicamentos, em que os participantes compartilham experiências comuns, falam sobre as dosagens adequadas, as combinaçôes possíveis e os efeitos colaterais adversos. O tratamento medicamentoso é considerado fundamental para garantir a remissão sintomática. Dentre as características principais das páginas analisadas estão: reciprocidade, ajuda mútua, o contato livre de estigmas entre os participantes, a tendência à empatia, ajuda ou compartilhamento de experiências comuns.

\section{O transtorno bipolar no Facebook e no Brasil}

A presença da bipolaridade também é notável no Facebook, maior rede social virtual do mundo. Esta tem 44 grupos sobre o transtorno bipolar provenientes do Brasil, Portugal ou países de língua espanhola, sendo 30 "fechados" e 14 "públicos", e cinco grupos provenientes de países de língua inglesa, sobretudo dos Estados Unidos, sendo todos fechados. Os textos de apresentação costumam caracterizálos como espaços de apoio e ajuda mútua, em que as pessoas podem compartilhar 
sentimentos, experiências, desabafar ou trocar informaçóes. Assim como ocorre na dinâmica usual do Facebook, a unidade de interação principal destas trocas é a "publicação" seguida de comentários e os usuários podem "curtir" as publicações e comentários que lhes interessarem ou chamarem a atenção. ${ }^{1}$

Foi possível identificar 26 grupos sobre o transtorno bipolar do Brasil no Facebook, além da presença de brasileiros em grupos estrangeiros. Foram encontrados também inúmeros sites e blogs, incluindo o da Associação Brasileira de Familiares, Amigos e Portadores de Transtornos Afetivos (ABRATA), fundada em 1999. Esta associação oferece atendimento aos bipolares pelo telefone, grupos de integração, grupos de apoio mútuo, palestras psicoeducacionais etc. Considerando este tipo de organização, bem como o número crescente de pessoas que participam dos grupos do Facebook e escrevem em blogs, pode-se sugerir que o tema ganhou visibilidade no país e que este diagnóstico vem participando do modo como muitas pessoas nomeiam e compreendem suas oscilaçôes emocionais. Apesar disso, náo há registro de artigos brasileiros que analisem os dispositivos virtuais sobre o transtorno bipolar na base de dados da Biblioteca Virtual em Saúde (BVS). Por fim, vale destacar que a expansão das organizaçóes sociais e redes virtuais em torno da bipolaridade ocorreu no contexto da mudança do diagnóstico de psicose maníaco-depressiva para transtorno bipolar (ROSE, 2013), o que enseja questôes sobre as relaçôes entre esses dois processos.

No Brasil, a ABRATA foi criada justo na época em que a terminologia "transtorno bipolar” se popularizava (Cf. MARTIN, 2009). A nova classificação afrouxou os critérios para a definição da bipolaridade, favorecendo o aumento do número de pessoas diagnosticadas. Ao mesmo tempo, concepçóes biológicas passaram a embasar a compreensão do transtorno, bem como associaçôes com a criatividade e a produtividade, levando a uma redução do estigma causado pela doença. Como mostra Martin (ibidem), enquanto o nome "psicose maníaco-depressiva" estava carregado de representaçôes ligadas ao descontrole e à loucura, a denominação "transtorno bipolar" é relacionada a disfunçôes cerebrais passíveis de manipulação química e a imagens valorizadas no capitalismo atual. De acordo com Lakoff (2005), a objetivação da bipolaridade permite situá-la como um elemento que o sujeito deve gerir, distinguindo um self vigilante -empreendedor de si - e o transtorno que ele busca monitorar. Nas palavras do autor: "a identidade diagnóstica torna-se uma arte de se autogovernar na medida em que encoraja uma vigilância prudente em relação a possíveis explosôes afetivas" (LAKOFF, 2005, p. 110, tradução nossa). 
Possivelmente, estes fatores contribuíram para que os próprios pacientes passassem a assumir a sua bipolaridade e a formar grupos virtuais no intuito de discuti-la. Nesse contexto, a internet é mais do que uma mera ferramenta de comunicação, mas atua como elemento propulsor de novos modos de veiculação do diagnóstico, estimulando a pluralização dos seus significados através das possibilidades geradas pela rede.

\section{Metodologia: a etnografia virtual}

Esta pesquisa é resultado de uma dissertação de mestrado e foi aprovada pelo Comitê de Ética do IMS/UERJ. Escolheu-se analisar o grupo sobre o transtorno bipolar brasileiro mais numeroso do Facebook (7.321 pessoas) pelo fato de a quantidade de comentários e a frequência de interaçôes entre os integrantes ser maior do que nos outros. Considerando a indicação de Hine (2000), a tarefa de definir o local do estudo se baseou no mapeamento dos grupos sobre o tema existentes na rede social virtual escolhida, que permitiu ter um panorama geral de cada um deles e, assim, escolher aquele (brasileiro) em que a circulaçáo de pessoas é maior.

Para obter as postagens de maior repercussão, o recorte do material foi feito com base no número de comentários gerados por cada publicação. No período de um mês (julho de 2015), foram coletadas as dez mais comentadas. Este tempo e esta quantidade foram definidos em função de observaçóes preliminares, que permitiram mapear a dinâmica e ritmo das interaçôes entre os participantes.

A tarefa de acompanhar esta rede exigiu a imersão no campo através de uma etnografia virtual. De acordo com Miller e Slater (2000), esta abordagem se baseia no engajamento multifacetado do pesquisador com o ambiente social estudado, promovendo um envolvimento de longo prazo entre os atores através de uma variedade de métodos. No presente estudo, houve não apenas a coleta e categorização das publicaçóes mais cotadas e seus respectivos comentários em eixos temáticos, como também diálogos entre a pesquisadora e o grupo despertados tanto pela postagem de apresentação da pesquisa quanto pelas mensagens individuais enviadas para solicitar a autorização dos participantes para publicar suas falas.

A análise deste material e das interaçóes envolvidas baseou-se nas perguntas que seguem: 1) Quais tratamentos e concepçôes sobre natureza/causas da bipolaridade são abordados pelos participantes? 2) O tema do estigma é discutido? 3) São os próprios pacientes que falam ou há outras pessoas se pronunciando? 5) Em que tons 
as pessoas falam do transtorno bipolar (positivo, negativo...)? 6) Quais os impactos do diagnóstico na trajetória de vida e na compreensão de si? 7) Há relatos sobre o percurso para se chegar ao diagnóstico? 8) Quais são as vozes de autoridade eleitas para falar sobre o tema?

\section{Resultados: análise dos eixos temáticos}

\section{Experiências dolorosas}

Das dez postagens analisadas, sete trouxeram este tipo de depoimento, fazendo referência a episódios depressivos, momentos de desespero, insônia, insatisfação consigo e ideação suicida. Houve o predomínio de concepçóes que situaram a doença como obstáculo ou entrave a ser contornado. A maioria dos depoimentos expunha algo da experiência de cada um, revelando um movimento de abertura para o grupo tal como analisado por Latalova et al. (2014) em relação às comunidades virtuais tchecas. Não havia um pedido de ajuda explícito, mas sim um desabafo. A visibilidade adquirida por estes relatos, tanto nas comunidades tchecas como no grupo do Facebook, deve-se ao fato de permitirem o compartilhamento de experiências comuns, estreitando o companheirismo entre os participantes. O predomínio deste tipo de interação mostra que uma das principais funçôes destas redes sociais é a busca de contato para apoio emocional, fenômeno também observado nas comunidades sobre autismo do Orkut (ORTEGA et al., 2013).

\section{Endosso e identificação}

Diante dos relatos de episódios depressivos ou outros momentos de dificuldade, os participantes frequentemente faziam comentários de endosso, afirmando entenderem o sofrimento que o autor da postagem estava passando ou reiterando o seu caráter doloroso em função de suas próprias vivências. A identificação mútua proporcionada por estas falas fica ainda mais clara quando se observa o modo como são construídas, com pronomes e verbos na primeira pessoa do plural. Vale lembrar que este mesmo tipo de construção gramatical apareceu nas postagens do fórum on-line espanhol estudado por Vayreda e Antaki (2009). Por esta via, o diagnóstico contribui para a produção de relaçôes de companheirismo entre os participantes.

Interaçóes semelhantes a essas foram identificadas nas páginas virtuais tchecas estudadas por Latalova et. al (2014), nas quais alguns participantes costumavam 
compartilhar suas experiências em situaçôes semelhantes às relatadas nas mensagens, construindo uma relação de empatia com os membros do grupo. Nos fóruns alemães sobre o transtorno bipolar, Schielein et al. (2008) também observaram que a empatia e o suporte são alguns dos principais mecanismos de autoajuda produzidos pelos participantes.

Tanto nos grupos tchecos e alemães, quanto no grupo do Facebook sobre a bipolaridade, a identificação pelo compartilhamento de experiências comuns é uma das principais formas de apoio entre os participantes. As mensagens de acolhimento só ganham sentido e legitimidade por serem feitas de um "sofredor" para outro, fortalecendo o suporte mútuo. Vale destacar que em alguns momentos são usados termos que denotam intimidade entre os participantes, como "linda (o)", "querida (o)", "amiga (o)", apesar de as pessoas não se conhecerem pessoalmente. A produção desta afetividade em torno da dor e da angústia não se resume ao grupo do Facebook, mas se ramifica através de outros dispositivos eletrônicos, como visto nas vezes em que os participantes se colocavam disponíveis para conversar individualmente, inbox, ou apresentavam grupos do WhatsApp como forma de ampliar os canais de apoio mútuo.

\section{Enfrentamento e manejo das emoçóes}

Apesar de apenas duas das publicaçôes terem endereçado um pedido de conselho ao grupo, todas elas incitaram mensagens de encorajamento e recomendaçôes objetivas sobre como agir para superar ou amenizar a dor. Como no grupo virtual espanhol pesquisado por Vayreda e Antaky (2009), conselhos náo solicitados pelo participante que fez a publicaçáo eram endereçados a ele, porém neste caso, nem sempre se restringiam a dicas biomédicas sobre o tratamento. Geralmente, eram feitos tanto comentários de motivação, sugerindo maneiras de vencer a tristeza e os pensamentos ruins, como recomendaçóes relacionadas a medicamentos e consultas psiquiátricas. A maioria das dicas para a superação do sofrimento buscava promover o seu alívio imediato de forma prática. Um exemplo foram as sugestóes de atividades prazerosas ou técnicas de respiração. Ao longo destas interaçôes, ficou subentendida a ideia de que não há cura para o transtorno bipolar, mas sim a possibilidade de superar as fases difíceis através de uma postura ativa e determinada. Por isso, muitos comentários desejavam força ou fé para enfrentar os momentos ruins e, em alguns casos, o próprio bipolar era caracterizado como alguém forte por estar em luta 
constante contra os males trazidos pelo transtorno. $\mathrm{O}$ foco não era buscar as razóes ou sentidos dos sintomas, mas sim promover o seu enfrentamento através do culto de pensamentos e atitudes positivas, bem como do uso de medicamentos.

Já na descrição do grupo os administradores encorajam os integrantes a postarem imagens bonitas, capazes de motivar os demais e causar sensaçôes agradáveis. Em seguida, afirmam que ser positivo é um benefício para todos e principalmente para quem o faz. Assim como Ortega et al. (2013) observaram nas comunidades do Orkut sobre autismo, o posicionamento dos usuários é bastante pragmático, endossando estratégias que têm resultados mais imediatos nos níveis comportamental e físico.

\section{Estigma}

Foi muito frequente a ideia de que a sociedade não dá importância à doença, não compreende o sofrimento envolvido na bipolaridade e só sabe julgar as pessoas diagnosticadas. Muitos se queixaram da intolerância e falta de cuidado em relação aos bipolares e alguns falaram do preconceito que eles próprios tinham em relação à doença quando receberam o diagnóstico e descobriram que teriam de iniciar tratamento psiquiátrico. Em alguns casos, a compreensão mútua e livre de preconceitos entre as pessoas diagnosticadas foi valorizada em contraponto ao julgamento perpetrado pela sociedade. Vale destacar que o tema do estigma também apareceu nas comunidades sobre autismo estudadas por Ortega et al. (2013), constituindo uma das categorias identificadas pelos autores.

\section{O saber pela experiência}

Frequentemente, as pessoas afirmavam que apenas quem sofre do transtorno o entende. Em alguns casos, esta valorização do saber baseado na experiência vinha acompanhada da queixa de que a sociedade não acolhe os bipolares e só sabe julgálos. Ao mesmo tempo que essas opiniôes apontavam para o estigma desta condição no meio social, analisado na seção precedente, elas também faziam do "sofrimento bipolar" uma fonte de conhecimento e sociabilidade, fortalecendo o senso de comunhão entre os participantes. Por se considerarem incompreendidos e malvistos pela sociedade, eles se aproximam uns dos outros para obter apoio daqueles com os quais se identificam. O protesto de alguns contra a minha pesquisa foi emblemático desta ideia, sugerindo que apenas as pessoas diagnosticadas poderiam ter a dimensão do sofrimento envolvido e falar sobre isso. Esta concepção se assemelha ao lema 
"nada sobre nós sem nós", promovido pelos estudos da deficiência, que nas últimas décadas desenvolveram um campo de reflexóes diferenciado do discurso dos médicos, educadores e outros especialistas. Inspirados neste movimento, ativistas autistas também nortearam a sua militância pelo valor "por autistas para autistas", enfatizando a necessidade de manter o debate entre aqueles que sofrem da condição e deixar os especialistas em uma posição secundária (ORTEGA, 2009).

O processo de construção identitária implicado nesta lógica tem características semelhantes às observadas no grupo do Facebook, promovendo o reconhecimento e autoafirmação dos indivíduos a partir da categoria diagnóstica. Nesse contexto, a própria doença permite a legitimação de um lugar de fala e saber que faz frente ao estigma. Nas palavras de Ortega (ibidem), "quando um grupo social é estigmatizado pela maioria da sociedade, a autodeclaração da identidade constitui um processo de coming out. A afirmação 'sou deficiente' (surdo, cego, autista, entre outros) constitui uma afirmação de autocategorização, um processo de subjetivação e de formação" (p. 69). Possivelmente em função desta lógica, o grupo é composto basicamente por pessoas diagnosticadas com bipolaridade e parentes. Os familiares buscam este espaço para aprender sobre o transtorno e, a partir disso, encontrar formas de lidar com seus parentes, reiterando a ideia de que a experiência daqueles que sofrem da doença é uma fonte de conhecimento sobre a mesma.

\section{Medicamentos}

Em relação aos tratamentos, as medicaçóes são o método mais usado e valorizado pelos participantes do grupo. Tal como nos fóruns de discussão alemães (BAUER et al., 2013; SHIELEIN et al., 2008), este tema é um dos mais comentados pelos participantes. Mesmo quando a discussão é sobre os efeitos colaterais, alguns pontuam que é preciso lidar com o problema, desaconselhando a interrupção do tratamento medicamentoso. Os poucos que dizem ter parado de tomar psicotrópicos geram receio e dúvidas por parte de outros participantes. Sobre este assunto, vale destacar que muitos desenvolvem um modo particular de tomar as medicaçóes e não seguem à risca as prescriçóes médicas. Por isso, o grupo torna-se fonte de dicas sobre o melhor remédio ou dosagem a ser ingerida. Em alguns casos, as pessoas pedem esse tipo de conselho para remediar angústias e dificuldades no momento em que aparecem. No âmbito destas trocas, os pacientes são investidos de autoridade para tratar de assuntos antes restritos à área médica. Eles próprios recomendam 
as medicaçôes e a dosagem que consideram adequadas para determinados casos e veiculam informaçóes que permitem aos companheiros de grupo contestarem seus psiquiatras, propondo mudanças no tratamento.

Este mesmo tipo de interação foi observado nos grupos virtuais tchecos (LATALOVA et al., 2014), em que os participantes frequentemente falavam sobre as combinaçôes possíveis de medicamentos, as dosagens apropriadas e seus efeitos colaterais. Assim como Epstein (2008) observou em sua análise sobre os movimentos de pacientes, estes conhecimentos mesclam o saber derivado das vivências de cada um com diferentes graus de conhecimento formal, produzindo formas de saber híbridas. Nesse processo, cria-se tanto um novo modo de manejar o sofrimento psíquico, quanto uma nova forma de relação entre médico e paciente, em que o último participa ativamente da consulta, fazendo reivindicaçôes e questionamentos.

Esta conjuntura pode ser relacionada às noções de "desprofissionalização" (HAUG, 1988; HARDEY, 1999) e "empoderamento" (BROOM, 2005). Na medida em que os integrantes do grupo formulam seu próprio saber com base em diferentes referenciais, eles alteram os padrōes de controle do conhecimento e subvertem hierarquias. É no interior desta dinâmica que passam a creditar a outros pacientes a autoridade para esclarecer dúvidas sobre medicamentos e demais aspectos da doença.

Provavelmente, o destaque dado às medicaçôes nestas discussões se relaciona aos saberes que vêm dominando o campo da psiquiatria nas últimas décadas. Desde a publicação do DSM III (1980), que substituiu a categoria "psicose maníacodepressiva" pelo "transtorno bipolar" com base em pesquisas de cunho genético e psicofarmacológico, as concepçóes neurológicas sobre o sofrimento psíquico têm sido amplamente difundidas pelos meios de comunicação, passando a integrar o imaginário sobre as doenças mentais. De acordo com a pesquisa etnográfica de Martin (2009), as pessoas frequentemente localizam as causas do transtorno bipolar em determinantes cerebrais e componentes genéticos, vendo nos medicamentos a esperança de cura.

\section{Porosidade das fronteiras diagnósticas}

Assim como observado por Ortega et al. (2013) em relação às comunidades sobre autismo no Orkut, muitos participantes descrevem uma via-crúcis para se chegar ao diagnóstico. Inúmeras pessoas foram classificadas em outras categorias nosológicas, como TOC, depressão ou borderline, antes do transtorno bipolar 
ou ao mesmo tempo. Estas confusóes entre a bipolaridade e outros distúrbios se relacionam ao alargamento dos critérios diagnósticos inaugurado pelo DSM III, que levou à classificação de diferentes tipos de oscilaçôes emocionais sob o rótulo de transtorno bipolar. Os efeitos dessas mudanças na nosologia psiquiátrica também se mostraram nas páginas de discussão tchecas analisadas por Latalova et al. (2014), em que grande parte das perguntas feitas buscava encontrar o diagnóstico correto e resolver possíveis confusões entre a bipolaridade e transtornos esquizoafetivos.

\section{Humor}

Ao longo das interaçôes, surgiram comentários bem-humorados sobre o transtorno bipolar, mostrando que este deixou de ser apenas objeto de medo e repulsa, como a antiga psicose maníaco-depressiva, e passou a gerar novas experiências e afetos. Em alguns momentos, os integrantes do grupo faziam ironias consigo próprios a partir das concepçóes atribuídas à bipolaridade.

\section{Direitos e cidadania}

Outro ponto abordado pelo grupo foi o direito à licença no trabalho. Nos comentários despertados por uma das publicaçóes, vários participantes aconselharam a pessoa a se afastar do emprego e uma afirmou que bipolaridade e trabalho não combinam. A consulta ao psiquiatra foi recomendada como forma de obter o laudo para comprovar a necessidade de afastamento. Desse modo, a licença no trabalho foi definida como direito do bipolar. Pode-se dizer que esta tendência caracteriza um tipo específico de cidadania, na qual reivindicaçôes a direitos civis pautam-se por argumentos médico-científicos. Considerando estas características, Petryna (2013), Rose e Novas (2005) a nomearam de cidadania biológica.

\section{A reificação do transtorno bipolar: ter $\mathrm{x}$ ser}

A compreensão sintomatológica do transtorno e a descontextualização do sofrimento psíquico transpareceram em muitas postagens no grupo. Frequentemente, os participantes se referiam à bipolaridade como uma entidade destacada de si ou um mal com o qual é preciso lidar, promovendo a sua reificação. As ideias de conviver com a doença ou batalhar contra ela são emblemáticas desta tendência, bem como o uso do verbo "ter" em vez do "ser" para conectar o sujeito ao transtorno. Além disso, já nas interaçôes deflagradas pela postagem de apresentação da pesquisa, o 
bipolar foi chamado de portador, reforçando a ideia de que a bipolaridade não faz parte do indivíduo, mas está anexada a ele. Como mostra a definição da palavra "portar", o transtorno seria algo que se leva, conduz ou carrega. A mesma ideia apareceu recorrentemente nos outros grupos sobre a bipolaridade identificados no Facebook. Além da noção de "portador", usou-se o termo "com” para ligar a pessoa ao transtorno e uma das descriçôes separou a bipolaridade da personalidade ao afirmar que se trata de uma doença e não de uma falha de caráter.

A reificaçáo do transtorno produzida por estas ideias se relaciona à incorporação de teorias neurobiológicas pela psiquiatria, que levou à representação das alteraçôes mentais como materialidades situadas no cérebro e, portanto, independentes do caráter e das escolhas individuais. A partir desta lógica, pode-se compreender a cisão estabelecida por muitos participantes entre o jeito de ser e a bipolaridade, bem como o fato de apenas os psiquiatras serem mencionados quando se fala no tratamento do transtorno. Vale lembrar que a referência a esses profissionais é quase sempre associada ao tratamento medicamentoso, ou, em outras palavras, ao controle psicofarmacológico dos sintomas. Como mostram Mayes e Horwitz (2005), foi nesta posição que a psiquiatria passou a ser situada com a revolução promovida pelo DSM III. Um dos poucos profissionais de outra área citado nas postagens foi o neuropsicólogo, corroborando a ideia de que os saberes ligados às neurociências têm dominado a compreensão dos transtornos mentais.

Junto às concepçôes neurológicas, teorias genéticas também se difundiram, contribuindo para definir a bipolaridade como uma condição inata e não adquirida. Embora esta ideia não tenha aparecido de forma explícita nas postagens, ela ficou subentendida nos relatos em que os participantes afirmaram ter bipolaridade desde sempre, na publicação em que a participante perguntou aos demais quando descobriram o transtorno e no comentário em que a pessoa mencionou familiares que também sofriam de bipolaridade para justificar a origem da doença. Tem-se como hipótese que tanto esta visão quanto a separação entre o transtorno e o modo de ser se relacionem à tendência a reificar as doenças mentais através de explicaçôes neurofisiológicas e genéticas.

\section{Redescrição de si a partir do diagnóstico}

A redescrição de si e da história pessoal sob a lente da categoria psiquiátrica apareceu de diferentes formas nos comentários. Por exemplo, a autora de uma publicação deu 
um novo significado ao fato de realizar muitas atividades após o psiquiatra afirmar que estava com depressão e não em fase mista. Além disso, ela e outra integrante do grupo demonstraram ter reconfigurado significativamente a compreensão de si após o diagnóstico de transtorno bipolar, descobrindo que todos os seus atos descontrolados e alteraçôes emocionais eram fruto da doença e não da personalidade.

A retomada do passado a partir da categoria psiquiátrica também foi observada nos grupos virtuais tchecos (LATALOVA et al., 2014). Nesses, os participantes costumavam fazer uma leitura retrospectiva sobre o desenvolvimento dos sintomas, descrevendo diferentes períodos de suas vidas que teriam sido afetados pela doença, mas que na época não havia sido possível reconhecer. No grupo estudado, os impactos da nomeação psiquiátrica sobre a experiência se revelaram ainda em dois relatos nos quais os integrantes afirmaram ter descoberto o que é uma vida com transtorno bipolar só após receberem o diagnóstico ou iniciarem o tratamento. Presume-se, portanto, que a classificação nosológica e a rede de cuidados que ela engendra tenham incidido sobre a percepçáo de si e o cotidiano destas pessoas de forma contundente, produzindo novos rumos e sentidos para suas vidas.

\section{Considerações finais}

Por reunir indivíduos em torno de uma doença específica, partilhando dicas e informaçôes sobre tratamentos e formas de lidar com os sintomas, pode-se dizer que se trata de um grupo de biossociabilidade (RABINOW, 1999, 2008). Nesse contexto, são construídas relaçôes de identificação mútua através do diagnóstico e de experiências em comum que alimentam a formação de vínculos afetivos mesmo sem o contato presencial. O suporte emocional produzido nestas trocas revelou-se a principal forma de interação entre os participantes. Como nas comunidades sobre autismo do Orkut (ORTEGA et al., 2013), a busca de contato para apoio emocional é uma das funções centrais deste espaço, que se torna, assim, um lugar de ajuda mútua.

Nestas interações, a experiência em primeira pessoa é legitimada como algo que nenhum profissional poderá jamais compreender. $\mathrm{O}$ saber partilhado pelos participantes leva à construção de teorias próprias sobre a doença e os modos mais apropriados de manejá-la, que não se restringem às verdades científicas divulgadas nos meios de comunicação (ibidem). Como nas comunidades do Orkut sobre autismo, a ausência de uma figura de autoridade médica permite a criação de uma autoridade baseada na experiência, de onde emerge a figura híbrida do leigo-especialista. 
Dos saberes formulados pelos participantes, destacam-se as recomendaçóes de práticas e pensamentos positivos para amenizar o sofrimento. Possivelmente, tanto os convites à superação de si e à atitude positiva, quanto a gestão das oscilaçóes emocionais através de remédios, relacionam-se aos valores difundidos na sociedade pós-moderna, como o culto à boa performance e à eficácia. As transformaçóes subjetivas não se realizam mais através do escrutínio da interioridade psicológica, mas sim de açôes concretas que buscam imprimir novas direçôes à vida do indivíduo, com eficiência. Viver a dor deixa de ser uma forma de autoconhecimento e se torna uma etapa a ser superada, que deve passar, tal como nos dizeres do grupo. O lugar da verdade não reside tanto naquilo que se sente, porém mais naquilo que se realiza. É a partir desse contexto que se podem compreender os conselhos formulados pelos participantes, como "levante, resista, lute!".

Do ponto de vista político-econômico, estas transformações se relacionam à assunção do neoliberalismo, que substituiu o planejamento social pela lógica do mercado, convocando os indivíduos a serem autônomos e a responsabilizarem-se por si com base no cálculo dos riscos (LAKOFF, 2005). Sob a atmosfera desta nova lógica, o advento de terapias e técnicas biomédicas de intervenção inaugurou novas possibilidades de ação e, assim, um novo horizonte de responsabilidades, diferente daquele produzido pelas teorias psicodinâmicas. A responsabilização não ocorre mais pela busca das origens do transtorno na história pessoal, mas pela correta administração das estratégias que objetivam o controle dos sintomas e alteraçôes emocionais.

Provavelmente, tanto as construçôes gramaticais em torno da bipolaridade, quanto as imagens da guerra ou convivência com a doença, recorrentes no grupo, associam-se à passagem de um paradigma que concebia as doenças mentais como frutos de fatores psicodinâmicos para outro em que o cérebro se tornou a sede destas patologias. Afinal, conforme foram localizadas nos circuitos cerebrais, estas adquiriram contornos e características de um objeto delimitado no espaço, com existência própria. Corroborando esta ideia, Lakoff (ibidem) afirma que a separação entre o transtorno e a identidade é operada pelas concepçóes biológicas. A partir delas, a doença deixa de ser situada no psiquismo para se tornar uma das dimensôes que compõe a pessoa. $\mathrm{O}$ "portador", por sua vez, tem de gerir esta dimensão assim como as outras, tornando-se um administrador das próprias experiências, que monitora suas alteraçóes emocionais para proteger-se dos excessos. 
A possibilidade de conferir um referente concreto a uma experiência difusa e angustiante permite ao indivíduo dar corpo àquilo que a religião, a dinâmica familiar ou o psiquismo não explicam mais. No grupo do Facebook, este fenômeno foi notado nas falas em que as pessoas afirmaram ter descoberto através do diagnóstico que muitos de seus atos eram fruto da doença e não da sua personalidade. Nesse processo, a categoria diagnóstica se torna um referencial identitário, formando bioidentidades (COSTA, 2004). Em relação a este conceito, porém, há um interessante paradoxo, pois a identidade que se constrói com base nos referenciais da psiquiatria atual não identifica o sujeito. Como visto anteriormente, a entidade nosológica é entendida como um elemento externo ao indivíduo, separado do jeito pessoal. Grosso modo, o "eu" não é bipolar, mas tem de viver com a bipolaridade. Ao mesmo tempo que as pessoas se reconhecem como portadoras do transtorno, explicando seus descontroles, ideaçóes negativas, dificuldades para dormir, períodos depressivos e maníacos com base nesta nomeação, elas diferenciam estes aspectos de si próprias. É como se encontrassem na linguagem psiquiátrica -associada às perspectivas biológicas - uma forma de se distanciar daquilo que, segundo elas, a sociedade não entende e só sabe julgar. $\mathrm{O}$ arrefecimento do estigma promovido por esta visão foi um dos motivos pelos quais os movimentos de pacientes se apropriaram da mesma, como indica Lakoff (2005).

Em suma, as interaçôes no grupo on-line revelam tanto as repercussóes do saber psiquiátrico e da nova lógica político-econômica sobre a forma como as pessoas concebem e sentem as variaçóes emocionais, quanto as expressôes que estas tendências ganham ao circularem na arena coletiva. Conforme participam do grupo, engajando-se na construção de sentidos para seus sentimentos e de dicas para o tratamento, os usuários constroem novas definições e formas de lidar com a bipolaridade, em uma dinâmica que inclui, mas ao mesmo tempo reconstrói a

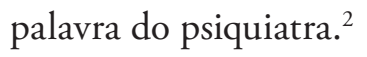

\section{Referências}

AYERS, S. L.; KRONENFELD, J. J. Chronic illness and health-seeking information on the internet. health: An Interdisciplinary Journal for the Social Study of Health, Illness and Medicine, v. 11, n. 3, p. 327-347, 2007.

BARKER, K. Electronic support groups, patient-consumers, and medicalization: the case of contested illness. J. Health Soc. Behav v. 49, n. 1, p. 20-36, 2008. 
BAUER, R. et al. Cyber-support: an analysis of online self-help forums (online self-help forums in bipolar disorder). Nord. J. Psychiatry v. 67, n. 3, p. 185-90, jun. 2013.

BROOM, A. Virtually He@lthy: The impact of internet use on disease experience and the doctor-patient relationship. Qual. Health Res, v. 15, n. 3, p. 325-345, mar. 2005.

COSTA, J. O vestígio e a aura: corpo e consumismo na moral do espetáculo. Rio de Janeiro: Garamond, 2004.

EPSTEIN, S. The Construction of Lay Expertise: AIDS Activism and the Forging of Credibility in the Reform of Clinical Trials. Science, Technology \& Human Values, v. 2O, n. 4, p. 408-37, 1995. . Patient groups and health movements. In: HACKET, E. L. et al. (Orgs.). The handbook of science and technology studies. 3. ed. Cambridge: MIT Press, 2008, p. 499-539.

FOX, N. J.; WARD, K. J.; O'ROURKE, A. L. The 'expert patient': empowerment or medical dominance? The case of weight loss, pharmaceutical drugs, and the internet. Soc. Sci. Med., v. 60, n. 6, p. 1299-309, 2005.

HARDEY, M. Doctor in the house: the internet as a source of lay health knowledge and the challenge to expertise. Sociol. Health Illn., v. 21, n. 6, p. 820-35, 1999.

HAUG, M. A re-examination of the hypothesis of physician deprofessionalisation. Milbank Quarterly, v. 66, Suppl. 2, p. 48-56, 1988.

HINE, C. Virtual Ethnography. London: Sage, 2000.

LAKOFF, A. Pharmaceutical reason: knowledge and value in global psychiatry. New York: Cambridge, 2005.

LATALOVA, K. et al. Bad on the net, or bipolars' lives on the web: analyzing discussion web pages for individuals with bipolar affective disorder. Neuro Endocrinol. Lett., v. 35, n. 3, p. $206-$ 12, 2014.

MARTIN, E. Bipolar expeditions: mania and depression in American culture. Princeton: Princeton University Press, 2009.

MAYES, R.; HORWITZ, A. DSM-III and the revolution in the classification of mental illness. Journal of the History of the Behavioral Sciences, v. 41, n. 3, p. 249-267, 2005.

MILLER, D.; SLATER, D. The Internet: an ethnographic approach. Oxford: Berg, 2000.

ORTEGA, F. Deficiência, autismo e neurodiversidade. Ciênc. Saúde Coletiva, Rio de Janeiro, v. 14, n. 1, p. 67-77, jan./fev. 2009.

et al. A construção do diagnóstico do autismo em uma rede social virtual brasileira. Interface (Botucatu), v. 17 n. 44, p. 119-32, 2013.

PETRYNA, A. Life Politics after Chernobyl. In: . Life Exposed: Biological Citizens after Chernobyl. Princeton: Princeton University Press, 2013, p. 1-33. 
RABINOW, P. Artificialidade e iluminismo: da sociobiologia à biossociabilidade. In: BIEHL, J. G. (Org.). Antropologia da Razão: ensaios de Paul Rabinow. Trad. de João Guilherme Biehl. Rio de Janeiro: Relume Dumará, 1999, p. 135-157.

. Afterwork: concept work. In: GIBBON, S.; NOVAS, C. (Ed.). Biosocialities, genetics and social sciences: making biologies and identities. New York: Routledge, 2008, p. 188-192.

; ROSE, N. O conceito de biopoder hoje. Política e trabalho, n. 24, p. 27-57, abr. 2006.

ROSE, N. Cidadãos biológicos. In: - A politica da própria vida: Biomedicina, poder e subjetividade no século XXI. São Paulo: Paulus, 2013, cap. 5, p. 188-220.

NOVAS, C. Biological citizenship. In: ONG, A.; COLLIER, S. J. (Ed.). Global assemblages: Technology, politics, and ethics as anthropological problems, Malden, MA: Blackwell, 2005, p. 439-63.

SCHIELEN, T. et al. Self-help from the cyberspace? An analysis of self-help forums for patients with bipolar affective disorders. Psychiatr. Prax., v. 35, n. 1, p. 28-32, jan. 2008.

TANIS, M. Health-Related On-Line Forums: What's the Big Attraction? Journal of Health Communication, v. 13, n. 7, p. 698-714, Oct./Nov. 2008.

VAYREDA, A.; ANTAKI, C. Social Support and Unsolicited Advice in a Bipolar Disorder Online Forum. Qualitative Health Research v. 19, n. 7, p. 931-942, 2009.

\section{Notas}

${ }^{1}$ Todas as informaçóes sobre o Facebook constantes neste artigo - número de grupos sobre o transtorno bipolar, número de participantes, recursos disponíveis nesta rede - correspondem ao período em que a pesquisa foi realizada (segundo semestre de 2015).

${ }^{2}$ L. M. Corrêa realizou a pesquisa e a redação do artigo. R. C. Lima orientou a pesquisa e revisou o artigo. 


\section{Abstract}

Bipolar disorder in the network: the construction of the diagnosis in an online group This article addresses the meanings and sociabilities that a Facebook group about bipolar disorder has produced on this diagnostic, through an online ethnography. Along with the growing penetration of psychiatric references in culture, bipolarity has been spreading through media such as the internet and participating in the ways many people interpret and feel their emotional oscillations. The ethnography sought to investigate the effects of diagnosis on self-understanding, the tones in which participants talk about it, treatments and conceptions about nature/causes of bipolarity addressed, etc. The ten most commented publications of the group in one month were analyzed and, based on the thematic axes identified, the following results were reached: most publications talk about painful experiences, placing bipolarity as an obstacle to be circumvented; endorsement and mutual identification by diagnosis are frequent in the group, encouraging companionship; medicines are the privileged resource in the treatment of the disorder, which is seen as incurable, but amenable to regulation; the cultivation of positive thoughts and attitudes are some of the strategies used to overcome difficult phases, showing a pragmatic attitude towards psychic suffering; bipolarity is defined as an entity external to personality.

> Keywords: bipolar disorder; health activism; internet; online community. 